\title{
Concept Development of a Multi Level Horizontal Shaft Impact Crusher
}

\author{
Nimisha Dave \\ M.Tech. Scholar \\ Oriental Institute of Science and Technology \\ Bhopal, M.P., India. \\ \& \\ Abhishek Jain \\ Assistant Professor \\ Department of Mechanical Engineering \\ OIST, Bhopal, India
}

\begin{abstract}
Crushers are one of the real size lessening gear that is utilized as a part of metallurgical, mechanical, and other comparative businesses. They exist in different sizes and limits which extend from $0.1 \mathrm{ton} / \mathrm{hr}$. to 50 ton/hr. They can be ordered taking into account the extent to which they can piece the beginning material and the way they apply strengths. In view of the system utilized crushers are fundamentally of three sorts to be specific Cone crusher, Jaw crusher and Impact crusher. Sway crushers include the utilization of effect instead of weight to pulverize materials. Here the material is held inside of an enclosure, with openings of the coveted size at the base, end or at sides to permit squashed material to escape through them. This sort of crusher is for the most part utilized with delicate materials such as coal, seeds or delicate metallic minerals. The instrument connected here is of Impact stacking where the season of use of power is not exactly the regular recurrence of vibration of the body. Since the sledges/blow bars are pivoting at a fast, the ideal opportunity for which the particles interact with the mallets is little, thus here effect stacking is connected. The pole is thought to be subjected to torsion and bowing. The pounding screen is additionally intended for ideal yield from the crusher An execution model is likewise considered for the level shaft sway crusher to discover the connection between the food, the crusher parameters and the yield parameters.
\end{abstract}

\section{INTRODUCTION}

A crusher is a gadget that is intended to decrease extensive strong pieces of crude material into littler lumps.

Crushers are ordinarily ordered by the extent to which they section the beginning material with essential crushers that don't have much fineness, moderate crushers having more huge fineness and processors diminishing it to a fine power.

A crusher can be considered as essential, optional or fine crusher relying upon the size decrease variable. a) Primary crusher - The crude material from mines is handled first in essential crushers. The info of these crushers is generally more extensive and the yield items are coarser in size. Illustration - Jaw crusher, Gyratory crusher, Impact Crushers, and so forth.

b) Secondary crusher- The smashed rocks from essential crusher are sent to these auxiliary crushers for further size lessening. Illustration:diminishment gyratory crusher, Cone crusher, plate crushers and so forth.

c) Fine crushers- Fine crushers have moderately little openings and are utilized to smash the food material into more uniform and better item. Illustration - Gravity stamp. 


\section{INTERNATIONAL JOURNAL OF SCIENCE ISSN: 2455-0108 | WWW.IJOSCIENCE.COM VOLUME II ISSUE I FEBRUARY 2016}

Table1. Comparison of different types of crushers [6]

\begin{tabular}{|c|c|c|c|c|}
\hline Type & $\begin{array}{l}\text { Hardness } \\
\text { (input } \\
\text { material) }\end{array}$ & $\begin{array}{l}\text { Abrasion } \\
\text { limit }\end{array}$ & $\begin{array}{l}\text { Reduction } \\
\text { ratio }\end{array}$ & Use \\
\hline $\begin{array}{l}\text { Jaw } \\
\text { crusher }\end{array}$ & $\begin{array}{l}\text { Soft - very } \\
\text { hard }\end{array}$ & No limit & $3: 1$ to $6: 1$ & $\begin{array}{l}\text { Extracted } \\
\text { materials, } \\
\text { sand } \\
\text { and } \\
\text { gravels }\end{array}$ \\
\hline $\begin{array}{l}\text { Conical } \\
\text { crusher }\end{array}$ & $\begin{array}{l}\text { Medium } \\
\text { hard - } \\
\text { very hard }\end{array}$ & Abrasive & $3: 1$ to $6: 1$ & $\begin{array}{l}\text { Sand and } \\
\text { gravels }\end{array}$ \\
\hline $\begin{array}{l}\text { Horizontal } \\
\text { shaft } \\
\text { impact } \\
\text { crushe } \\
\mathrm{r}\end{array}$ & $\begin{array}{l}\text { Soft } \\
\text { mediu } \\
\mathrm{m} \text { hard }\end{array}$ & $\begin{array}{l}\text { Slightly } \\
\text { abrasive }\end{array}$ & $\begin{array}{ll}10: 1 & \text { to } \\
25: 1 & \end{array}$ & $\begin{array}{l}\text { Extracted } \\
\text { material, } \\
\text { sand } \\
\text { and } \\
\text { gravels }\end{array}$ \\
\hline $\begin{array}{l}\text { Vertical } \\
\text { shaft } \\
\text { impact } \\
\text { crushe } \\
r\end{array}$ & $\begin{array}{l}\text { Medium } \\
\text { hard - } \\
\text { very hard }\end{array}$ & $\begin{array}{l}\text { Slightly } \\
\text { abrasive }\end{array}$ & $6: 1$ to $8: 1$ & $\begin{array}{l}\text { Sand } \\
\text { and } \\
\text { grave } \\
\text { ls }\end{array}$ \\
\hline
\end{tabular}

\section{LITERATURE RIVIEW}

It was additionally discovered that the molecule going into the breakage process obtains consistent breakage until it comes up short the arrangement capacity for breakage. Henceforth bigger the guardian molecule the bigger is the quantity of breakage procedure [1]. Because of the dynamic nature sway breaking it was found that the characterization capacity relies on upon the crusher outline parameters (shape parameter and effect vitality) and food rate furthermore on the material quality parameters. The execution model can anticipate the item estimate appropriation with sensible exactness notwithstanding when critical varieties in both the rotor speed and nourish are forced. The particular effect vitality for a Horizontal shaft crusher is not as much as that for a vertical shaft crusher [2]. It was likewise discovered that no other power follows up on the molecule amid its free fly from the rotor hammer effect to the divider effect. It was likewise discovered that the motor vitality is the overwhelming type of vitality. The profundity of infiltration can be expanded by diminishing rotor speed or expanding the stature of fall. For viable smashing the speed of free fall of the bump ought to be adequate to achieve the center of head of sledge or the effect zone. The particles with a littler grain size have higher quality [2]. From the energy of the sledge/blow bar pivot it was discovered that lessening the quantity of blow bars on the rotor not just decreases the aggregate weight and cost by likewise gives enough spaces between the two mallets so that the bit of material admitted to every line of blow bars experiences a devastating surface equivalent in size to a constant bed over the whole width of the rotor and thus a bigger surface than that of the first course of action by the greatness of the crevices between the sledge/blow bar heads will be accessible. We can now effectively ascertain the perfect number of mallets. Additionally for the measure of the material required we can discover the ideal velocity of turn of the rotor.

\section{OBJECTIVE}

Our goal is to outline different segments of an Impact crusher like muti level drive instrument, shaft, rotor, multi level hammer, packaging, different shape siev at release level and release system which will be helpful in minimizing weight, cost and amplifying the limit furthermore do their investigation.

\section{HORIZONTAL SHAFT IMPACT CRUSHER}

Here the food material is smashed by very thorough effects beginning in the snappy rotational development of sledges/bars altered to the rotor. The particles are then squashed inside the crusher as they crash against crusher parts and against each other, delivering better, better-formed item. Modifying the separation between effect edge and rotor casing can change the shape and size of the yield.

In an effect crusher the breakage happens in a lesser time range when contrasted with the funnel shaped or jaw crushers. So here the nature and extent of powers and in addition the vitality disseminated because of sway breakage is not quite the same as that of the relative moderate breaking that happens because of pressure or shear in other kind of crushers. 


\section{INTERNATIONAL JOURNAL OF SCIENCE ISSN: 2455-0108 | WWW.IJOSCIENCE.COM VOLUME II ISSUE I FEBRUARY 2016}

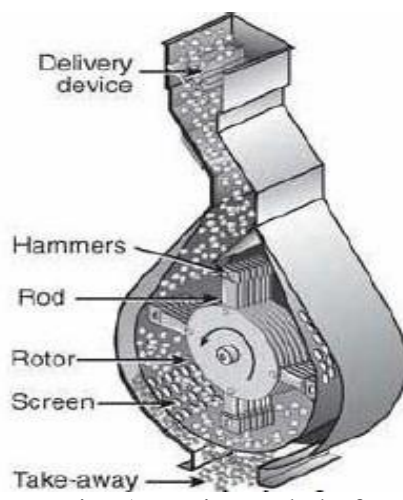

Fig. 1 Horizontal shaft impact crusher [8]

\section{PROCESS DESCRIPTIO} $\mathbf{N}$

The Impact Crusher Machine rotor rotates in settled heading by method for driving activity of triangle belt that associates with engine. Above rotor, there are sets of suspended effect plates. Material goes into the devastating chamber through the charging gap and sustaining guide plate. The blow bars settled on rotor strikes the food material onto sway plate and after that tumble from it to commonly stun material pieces. In this manner, material will be moved repetitively and more than once in the devastating chamber that is made out of rotor, effect plate/iron blocks, hammers/pass up method for which exceptional stun wonder will act prevalently, and the material will be pulverized along its regular break and thus swell. The hole between effect plate and mallet/blow bar can be balanced by necessity by conforming the edge and separation of the effect blacksmith's irons. Item yield is effortlessly controlled by changing the rotor speed, data nourish rate and the granulating screen arrangement. [8]

VI.

PROPOSED

DESIGNS

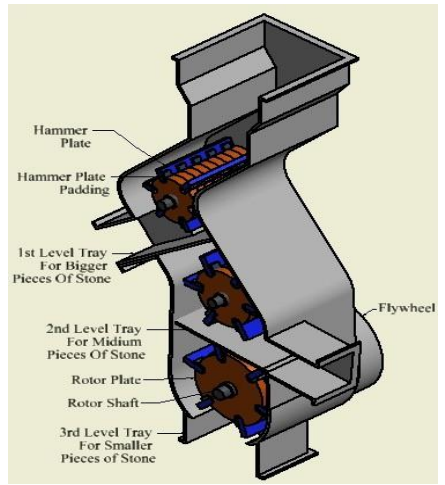

Fig. 2 Multi Level Horizontal shaft impact crusher

\section{CONCLUSION}

The Rotor mallets were checked for their bowing and shear push and were found inside of as far as possible in the greatest burden condition. The rotor plate was likewise checked for shear push and was discovered safe. The blacksmith's irons were checked for twisting and shearing qualities and were found under the breaking points of disappointments. The rotor shaft was checked for torsion and bowing and was discovered safe. The Driving system of rotor was planned in a manner that the $\mathrm{V}$ belt was sheltered and could transmit obliged velocity to the rotor from the engine. A fitting packaging structure is likewise proposed for lodging the crushers' get together.

There is part more to do in this machine to upgrade the execution of it. For example, examination ( static and element), liveliness to watch that every one of the parts are working legitimate or not furthermore to check crash. What's more, parcel more to do.

\section{REFERANCE}

1. http://ethesis.nitrkl.ac.in/2148/1/107ME037Im pact_Crusher.pdf

2. S. Nikolov, Modeling and simulation of particle breakage in impact crusher, International journal of mineral processing, $74 \mathrm{~S}$ (2004) S219-S225

3. N. Djordjevic, F.N Shi *, R.D. Morrison, Applying discrete element modeling to vertical and horizontal crushers and horizontal shaft impact crushers, Minerals engineering, 16 (2003) pp. 983-991

4. Chowdhury Ranajit, Techno economic benefit by designing sinter hammer crusher with energy model by reducing number of hammer head with improvement of crushing index in Indian steel plant ( PHD (eng), FIE, FIPHE, FIC)

5. Jarmo Eloranta, Crushing and Screening Handbook, Kirjapaino hermes, Tampere, sept 2006

6. R.S. Khurmi \& J.K. Gupta, Text book of Machine Design, 788-

790, 2005 edition

7. Http://en.wikipedia.org/wiki/Crusher 


\section{INTERNATIONAL JOURNAL OF SCIENCE ISSN: 2455-0108 | WWW.IJOSCIENCE.COM VOLUME II ISSUE I FEBRUARY 2016}

8. Http://www.crushercrusher.com/

9. Http://processsystemsdesign.com/equipmentcrusher-crushing- machine-equipment.html

10. Http://www.infominerals.com/impactcrusher.html

11. Attou A., Clepkens, o., Gustein R., 1999. Modelisation de la fragmentation de matiere solide dans un concasseur a chocs a axe horizontal. In: C.T.P. Report TP. 909.99. pp. 1928

12. Csoke, B., Racz j., 1998. Estimation of the breakage and selection functions for comminution in hammer mill. In: Proceedings of the 9th European Symposium on Comminution, ALbi, France, 1. Pp. 393-401.

13. [King, R.P. (2000), continuing education course on simulation and modeling of mineral processing plants, Univ. of Utah course, Tech. notes 5, Crushers, pp.5]

14. Jarmo Eloranta, Chart B, Crushing and Screening Handbook, Kirjapaino hermes, Tampere, sept 2006, sc 4-11, 4-12

15. Jarmo Eloranta, Chart C Crushing and Screening Handbook, Kirjapaino hermes, Tampere, sept 2006, sc 4-13, 4-14

16. Jarmo Eloranta, Chart D, Crushing and Screening Handbook, Kirjapaino hermes, Tampere, sept 2006, sc 4-13, 4-14

17. Jarmo Eloranta, Chart G, Crushing and Screening Handbook, Kirjapaino hermes, Tampere, sept 2006, sc 4-13, 4-14

18. Jarmo Eloranta, Table for D,E,F,H,I,K,L, Crushing and

Screening Handbook, Kirjapaino hermes, Tampere, sept 2006, sc

4-11, 4-14 